UCRL- 91648

PREPRINT

\title{
ICF REACTOR ECONOMICS: IDENTIFYING THE HIGH LEVERAGE DESIGN FEATURES
}

Wayne R. Meier

William J. Hogan

This paper was prepared for submittal to the 6th ANS Topical Conference on Technology of Fusion Energy held in San Francisco, California on March 3-7, 1985

February 28, 1985

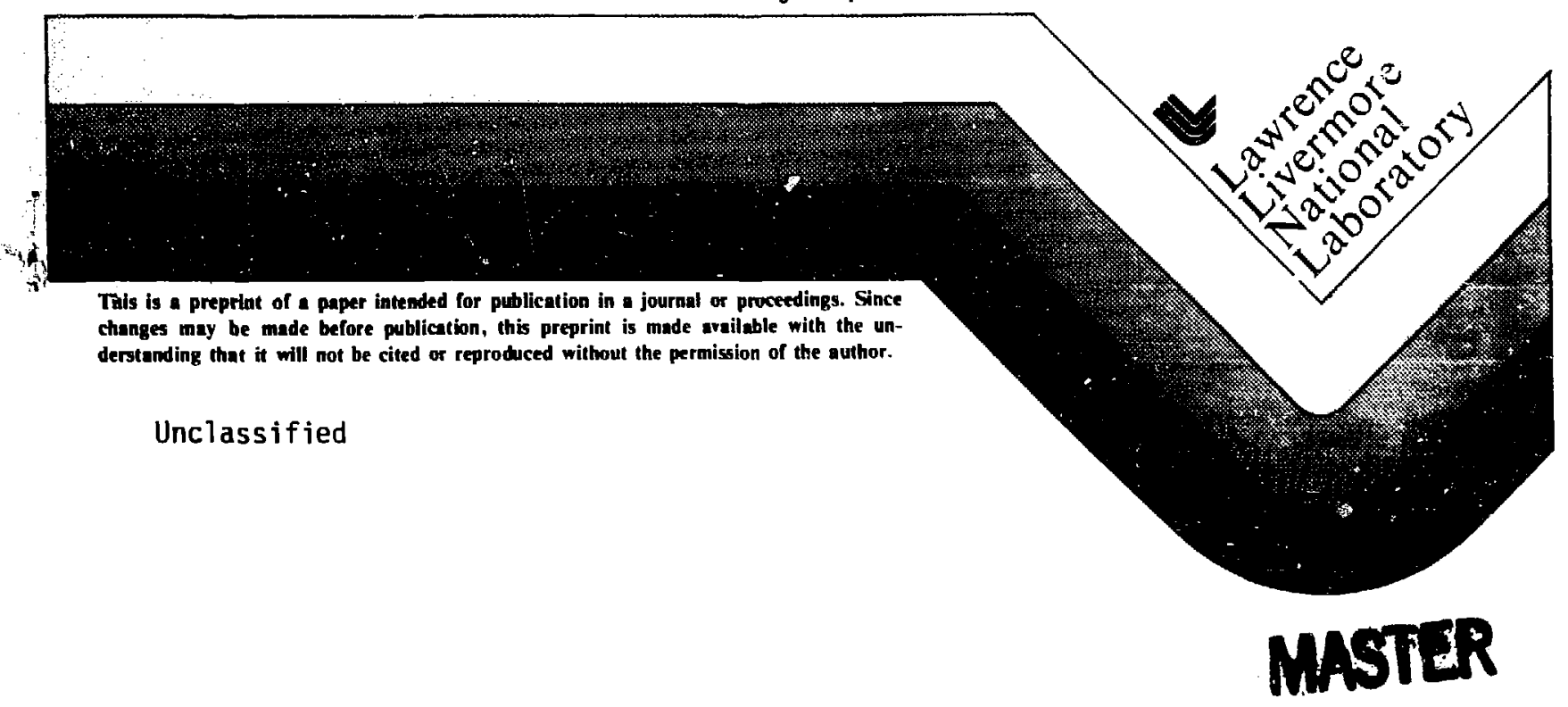


ICF REACTOR ECONOMICS: IDENTIFYING THE HIGH LEVERAGE DESIGN FEATURES*

WAYNE R. MEIER and WILLIAM J. HOGAN

Lawrence Livermore National Labnratory

UCRL -91648

Livermore, California 94550

(415) 422-5473

DE85 010001

\section{ABSTRACT}

Parametric studies were carried out for a heavy ion beam (HIB) fusion electric power plant to investigate the effects on the cost of electricity (COE) of varlations in several design parameters. In particular, we examined the effects of maximum achievable chamber pulse rate, driver cost, iarget gain, electric conversion efficiency, and net electric power. We find that with a combination of improvements over our base case, HIB fusion can be economically competitive with other future power sources.

\section{INTRODUCT ION}

One of the primary objectives of the ICF Applications Group is to develop power plant concepts that will be economically competitive with other long-term electric power producers such as fission and coal. We are developing systems models for ICF power plants that allow us 1) to ident1fy design features that have the highest leverage for improving ICF economics and 2) to do first order economic comparisons with other power sources.

While economic factors are not the only ones that will be considered in decision making about future power sources, other factors, such as safety, environmental impact, and pubilc acceptance may not weigh heavij.y uriless ICF also appears to be economically competitive. The definition of economic competitiveness is subject to much debate. A cominon figure of merit is the COE. Because of economies of scale, the COE decreases monotonically with increasing power plant size. Therefore, cther figures of merit, which reflect the total capital investment, must also be considered. In this paper, however, we limit our discussions to the COE as the figure of merit.

* Work performed under the auspices of the u's DOE by the Lawrence Livermore National Laboratory under Contract No. W-7405-ENG-38
In this paper we consider a heavy ion beam fusion power plant that consists of a driver, a target factory and one or more power units. A power unit is defined as all the buildings and equipment needed to generate electric power given that $\mathrm{ti}_{\mathrm{h}}$ target and beams are delivered to the reaction chamber. Each power unit may have several reaction chambers where the fusion pulses occur. The maximum achievable pulse rate in a single chamber is limited. Therefore more than one reaction chamber may be required to achieve the desired output of a single power unit. We distinquish between multiple power units and multiple reaction chambers so we can examine separately the effects of increasing the number of reaction chambers at a constant net power and of increasing the power level by driving more power units with a single driver.

\section{COSTS}

The cost models we used in this study are reported in detail in Ref. 1. The essence of the models is summarized here.

\section{Power Unit cost}

The model we have assumed for the HIB fusion power plant uses a conventional steam cycle to produce electricity. Other than the fusion reaction chamber itself, the rest of each power unit look essentially like a fission power plant outside the reactor vessel. Therefore, our cost scaling models are derived from recent estimates for future fission plants. Fission power plants recently completed and currently under construction are significantly more expensive than coal-fired power plants. United Engineers and Constructors and researchers in the Engineering Technology Division at Dak Ridge National Laboratory have, however, estimated the cost of nuclear power plants for the 1990 's based on the presumed effects of licensing reform. 2,3 The 1990 's nuclear plants have direct capital costs that are essentially equal to those of coai plants. We 
assume that the fusion plant can achieve similar direct capital costs for those elements not unique to fusion. On this basis, the direct capital cost of a 1 GWe power unit is $\$ 0.7 \mathrm{~B}$.

As previously indicated, each power unit may have more than one reaction chamber. To account for this in our cost algorithms, we break down the direct capital cost into three parts, the containment building cost, the steam supply system (SSS) cost, and the remainder of the power unit cost. Reference 3 gives a detailed break-down of the cost of the PWR for the 1990's. It shows that the reactor containment building cost is 7.5\% of the total direct cost, and the SSS accounts for $18.2 \%$ of the total direct cost. We allocate additional containment building space and SSS equipment for each additional fusion chamber using these same fractions. The direct capital cost of the power unit can be written as

$$
\begin{aligned}
c_{\text {ud }}= & 0.705\left[0.743 P_{9}^{0.6}+0.075 P_{c}^{0.5} N_{c}\right. \\
& \left.+0.182 P_{C}^{0.6}{ }_{N}\right] \$ B
\end{aligned}
$$

where $P_{g}$ is the gross electric power for one power unit, $P_{c}$ is the gross electric power associated with each chamber, and $N_{c}$ is the number of chambers per power unit. Hence, $P_{c} N_{c}$ is equal to $P_{g}$ for each power unit. Experience has shown that there are savings in both the direct and indirect capital costs for multi-unit power plants. $2,3,4$ Typically, each additional unit has a direct capital cost equal to $80 \%$ of the first unit on the site, and an indirect capital cost equal to $60 \%$ of the indirect costs for the first unit. These factors are included in our analyses.

\section{Oriver Cost}

The cost of a leavy Ion beam driver have been estimated based on RF accelerator ${ }^{5}$ and Induction linac ${ }^{6}$ technology. Using the results given in Ref. 6 , the driver direct capital cost is given by

$$
C_{d d}=0.64 E_{d} 0.4+0.1\left(N_{c} N_{U}-1\right) \$ B,
$$

where $E_{d}$ is the driver beam energy in $M J$. The second term in Eq. 2 accounts for the additional cost of transporting beams to the individual reaction chambers.

\section{0ther Factors}

In addition to the driver and power unit costs, we include $\$ 100 \mathrm{M}$ for the direct capital cost of the target factory and le/target for consumable materials. The total capital cost is 1.9 times the direct capital cost. This factor accounts for contingency (10\%), indirect construction costs (50\%), and interest during construction (15\%). Annual $0+M$ costs equal to $2 \%$ of the total capital cost are also included. The fixed charge rate used in our constant dollar analysis is $10 \%$, and the plant capacity factor is $70 \%$.

RESULTS

The base case parameters used in our calculations are a net power per power unit $\left(P_{n}\right)$ of $1 G W_{e}$, one power unit per plant $\left(N_{u}=1\right)$, maximum chamber pulse rate $\left(\omega_{\mathrm{cm}}\right)$ of $10 \mathrm{klz}$, and an electric conversion efficiency $\left(n_{C}\right)$ of $40 \%$.

Figure 1 shows the net power, driver power, auxiliary power, and gross electric power as a function of the driver pulse rate for the base case. The driver power requirement increases with increasing pulse rate. This follows since a higher pulse rate corresponcis to a lower target gain, and, therefore, more power must be recirculated to run the driver. The gross electric power required to maintain a net output of $1.0 \mathrm{GW}_{\mathrm{e}}$ increases from 1.15 to $1.45 \mathrm{GW}_{\mathrm{e}}$ as the driver pulse rate increases from 5 io $50 \mathrm{~Hz}$.

Maximum Chamber Pulse Rate as a Parameter

The COE as a function of the driver pulse rate is shown in Fig. 2 for four different maximum chamber pulse rates; $\omega_{\mathrm{cm}}=5,10$, 20 , and $>50 \mathrm{~Hz}$. The discont inuities, which occur every $\omega_{\mathrm{cm}} \mathrm{Hz}$, reflect the cost of additional 555 equipment containment building space, and beam transport lines incurred each time an additional chamber is added.

Focusing on the base case with $\omega_{\mathrm{cm}}=10 \mathrm{~Hz}$, we see that the COE initially decreases with increasing driver pulse rate. This is due to the fact that the driver cost decreases with increasing driver pulse rate since higher pulse rates correspond to lower driver energies. The minimum COE is $7.0 \mathrm{x} / \mathrm{kW}_{\mathrm{e}} \mathrm{h}$ for the base case and occurs at 10 $\mathrm{Hz}$. At this point, the driver energy is $3 \mathrm{MJ}$ and the gross electric power is 1.18 Gie.

It is interesting to note how flat the $>50 \mathrm{~Hz}$ line is. If a chamber could be designed to operate at an unlimited pulse rate (or if there were no cost associated with increasing the number of chambers), the minimum COE would be $6.75 \mathrm{e} / \mathrm{kW}_{\mathrm{e}} \mathrm{h}$ which is realized between 25-30 $\mathrm{Hz}$. Hence the $10 \mathrm{~Hz}$ limit on chamber pulse rate increases the $\mathrm{COE}$ by less than $4 \%$. If the chamber pulse rate is limited to $5 \mathrm{~Hz}$, the COE is $7.4 \mathrm{E} / \mathrm{kW} \mathrm{eh}$, or less than $10 \%$ higher than the $6.75 \mathrm{e} / \mathrm{kW}_{\mathrm{e}} \mathrm{h}$ minimun. The curves also rise at high pulse rates since the cost of the power unit is increasing with increasing gross power. 


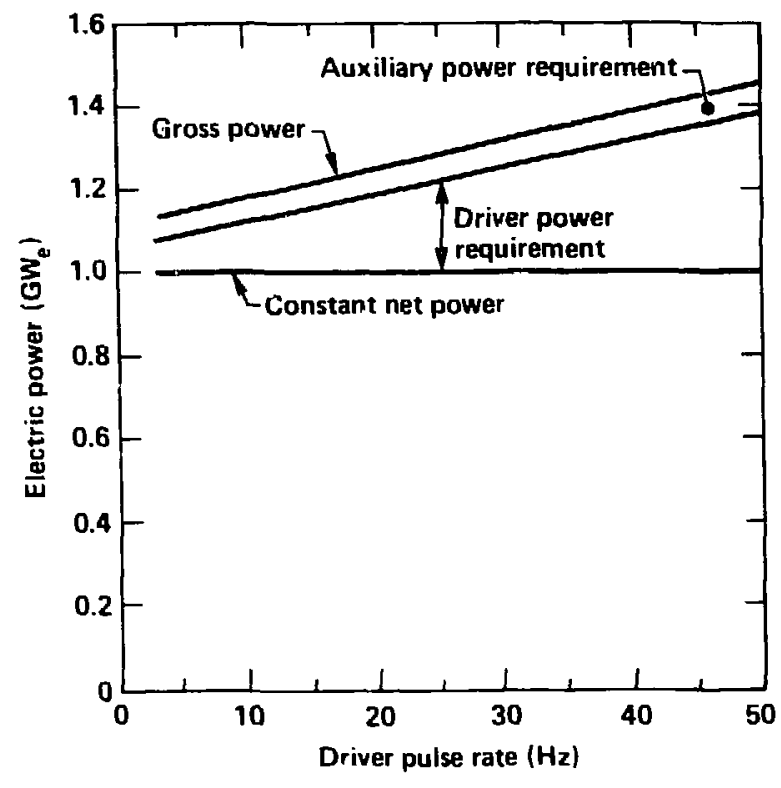

Fig. 1 The gross electric power required to maintain a constant net electric power increases with increasing driver pulse rate.

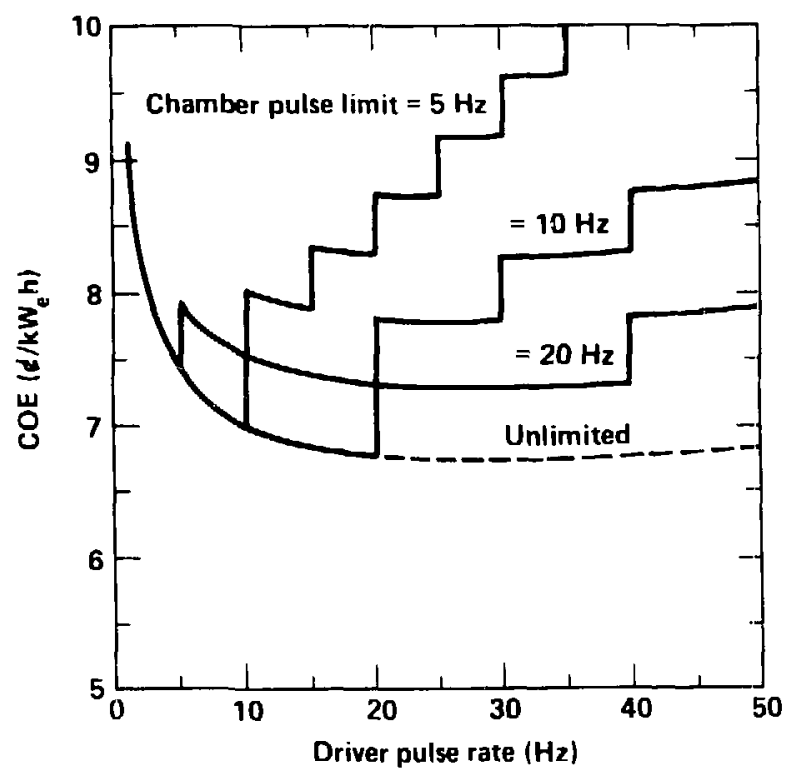

Fig. 2 The COE decreases as the driver pulse rate increases until the chamber pulse limit is reached.

\section{Driver Cost as a Parameter}

Figure 3 shows the sensitivity of the COE to the cost of the driver. The three curves, from top to bottom, are the base case, the driver cost reduced by $25 \%$, and the driver cost reduced by $50 \%$, respectively. The cost reductions gre applied to the total driver cost including the additional beam transport lines required for power units with more than one chamber. In all three cases the minimum COE occurs at $10 \mathrm{~Hz}$. Since the driver cost is about half of the total capitai cost, reducing the driver cost leads to significant savings in the COE. Each 25\% reduction in the driver cost gives a $13 \%$ reduction in the CDE.

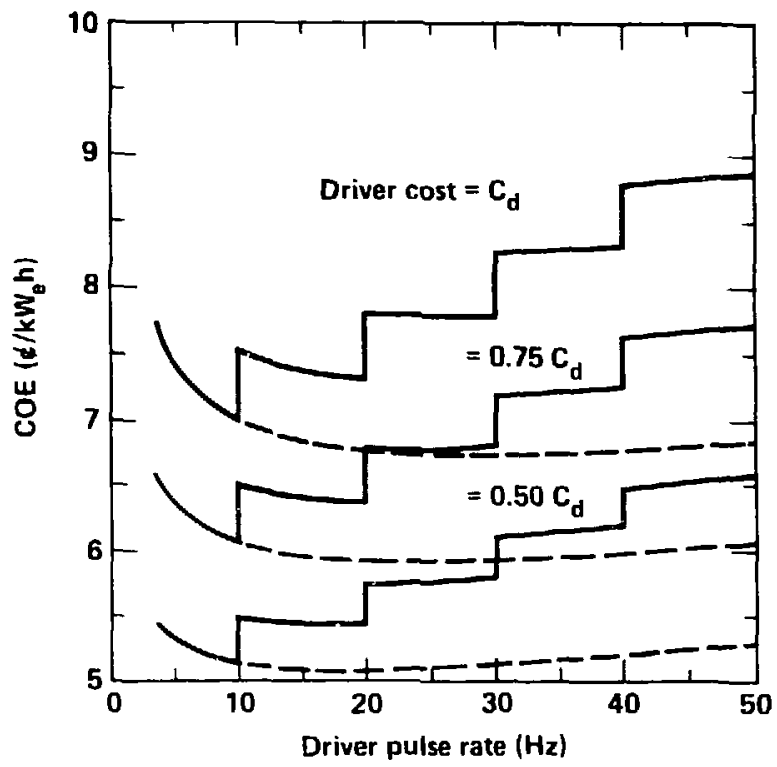

Fig. 3 Reducing the driver cost reduces the COE.

The dashed curves show that if the chamber pulse rate is unlimited, the opcimum driver pulse rate decreases with decreasing driver cost. In addition, the COE becomes less sensitive to oriver pulse rate, i.e., the curves tend to flatten out.

\section{Target Gain as a Parameter}

The reference target gain corresponds to the $r^{3 / 2} R=0.01$ case given in Ref. 7 . It is fit by the expression,

$$
G=20+113 \ln \left(E_{d} / 1.7\right) \text {. }
$$

We also investigated the effect of improving the target performance. He assume that the driver energy required to achieve a given 
target gain is reduced by a factor of three. This is consistent with estimates for polarized fuel. 8 at $10 \mathrm{~Hz}$ the COE is reduc 30 by $12 \%$. With no limit on chamber pulse rat $\geqq$, the COE minimum shifts toward higher pulse rates as galn improves at lower driver enrygy. Furthermore, in this case the COE also bacomes more sensitive to pulse rate.

\section{Conversion Efficiency as a Parameter}

We examined the effect of increasing the electric conversion efficiency by assuming that the conversion efficiency can be increased without increasing the cost per $k W_{t}$. We found that increasing the conversion efficiency from 40 to $60 \%$ only reduces the COE by $12 \%$. Remember that the ret electric power is held constant, therefore, a more efficient power unit is smaller and suffers an economy of scale penalty. That is, the cost per $\mathrm{kW}_{\mathrm{t}}$ is only the same for plants of equal thermal power.

\section{Píant Power as a Perameter}

As noted previously, there are two ways to consider net plant power as a variable. The number of units can be set equal to one and we can vary the power of the unit. On the other hand, we can keep the power of each unit constant and vary the number of power units in a plant.

Firsl, we consider a single-unit plant. Figure 4 shows the COE for three different net power outputs, $0.5,1.0$ and $2.0 \mathrm{GW}_{\mathrm{e}}$. The COE from the $0.5 \mathrm{GW}$ plant is $66 \%$ more than the base case at $10 \mathrm{~Hz}, 1 . e ., 11.6$ versus $7.0 \mathrm{e} / \mathrm{kW}_{\mathrm{e}} \mathrm{h}$. The $2.0 \mathrm{GW}$ plant produces electricity at $4.3 \mathrm{e} / \mathrm{kW}_{\mathrm{e}} \mathrm{h}$ or $39 \%$ less than the base case. It is clearly advantageous, in terms of the COE, to use the driver to prociuce as much power as possible. Other considerations such as following load growth and minimizing total capital investment may favor smaller net powers.

We also considered the advantages of using a single driver and target factory to operate more than one power unit. At a driver pulse rate of $20 \mathrm{~Hz}$, a two-unit, $2 \mathrm{GW}$ power plant produces electricity at $4.8 \mathrm{e} / \mathrm{kw} \mathrm{e}$, or $31 \%$ lower than the single-unit, 1 GW plant. A four-unit, $4 \mathrm{GW}_{\mathrm{e}}$ power plant reduces the $\operatorname{COE}$ to $3.6 \mathrm{k} / \mathrm{kW} \mathrm{h}$, or $49 \%$ lower than the single-unit plant. The total capital investment, however, increases as the number of units is increased. The total capital costs for the 1,2 and 4 unit plants are $\$ 3.558$, $\$ 4.81 \mathrm{~B}$, and $\$ 7.35 \mathrm{~B}$, respectively.

We found that as the number of units Increase, the COE becomes less sensitive to the driver pulse rate. In fact the four-unit

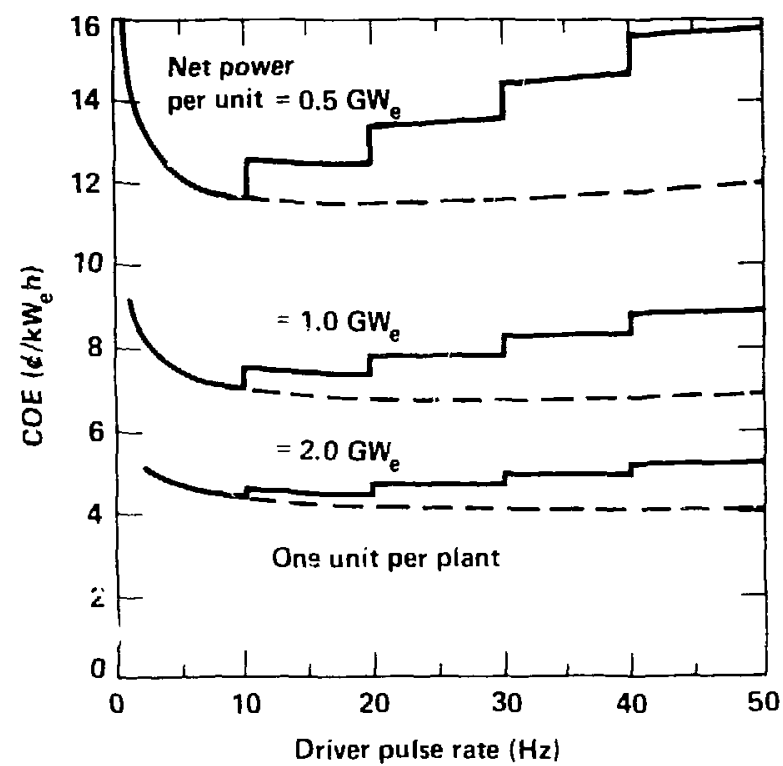

Fig. 4 The COE decreases as the net power of the plant increases.

plant could operate at a driver pulse rate of $12 \mathrm{~Hz}$ and still be within 5\% of its minimum cot. The required chamber pulse rate in this case is only $3 \mathrm{~Hz}$.

Figure 5 shows the COE as a function of the total net power for plants made up of different size units, $0.5,1.0$, and $2.0 \mathrm{GW}_{\mathrm{e}}$ net. The COE from a $1.0 \mathrm{GW}_{\mathrm{e}}$ power plant consisling of two $0.5 \mathrm{GW}$ units and a single driver is $7.7 \mathrm{e} / \mathrm{kH} \mathrm{eh}$. This is $10 \%$ higher than the COE from a single-unit power plant generating $1 \mathrm{GW}_{\mathrm{e}}$. This higher $\operatorname{COE}$ is the result of the economies of scale in the power unit cost and the additional cost of beam transport lines for the two-unit plant. The COE from a 2 GW power plant with a single unlt is $4.3 d / \mathrm{kW} h$ compared to $4.8 d / \mathrm{kW}_{\mathrm{e}} \mathrm{h}$ for a two-unit plant, and $5.8 \mathrm{~d} / \mathrm{kW}_{\mathrm{e}} \mathrm{h}$ for a four-unit plant.

We see that at a fixed net power, the COE is lower for a single-unit plant than for a mult1-unit plant. The multi-unit plant does, however, achleve most of the economy of scale benefits of a single large unit. For example, going frum 0.5 to $2 \mathrm{GW}_{\mathrm{e}}$ in single-unit plant reduces the COE by $63 \%$, compared to the $50 \%$ reduction achieved by a four-unit plant. An advantage of the multi-unit plant is its operulional flexibility. The plant can begin to aperate and produce revenues from one unit while decisions are pending on the need for 


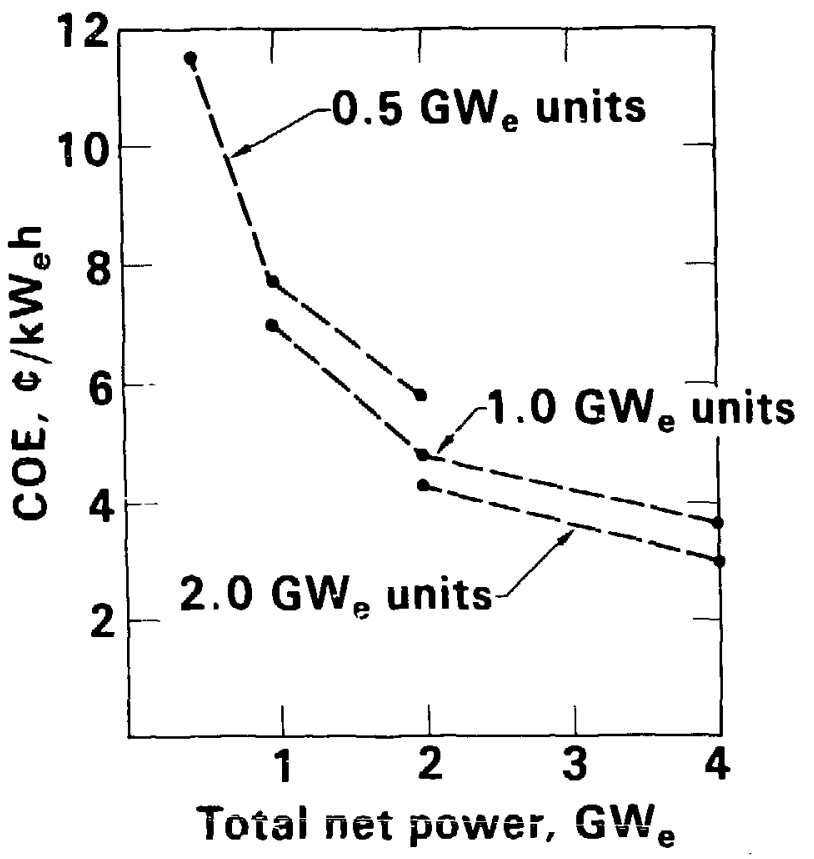

Fig. 5 For the same net power, plants with fewer, larger power units have lower COE.

addilional units. Capital costs for the future units are, of course, also deferred.

\section{Several Parameters Simultaneously}

Most of the parameters considered have a mouest impact on the COE. No single impruvement considered is able to reduce the $\mathrm{COt}$ to the point where it would be competitive with coal $\left(4.6 \mathrm{~d} / \mathrm{kW}_{\mathrm{e}} \mathrm{h}\right)$ or nuclear (3.5e/kW $\mathrm{k}$ ) power. 2 Hence it is important to make advances in as many areas as possible. In Fig. 6 when we considered several simullaneous improvements, namely, a driver $\operatorname{cosl}$ reduction of $25 \%$, the improved target gail, un clectric conversion efficiency of $50 \%$, and two-unit power plants, we found that a $2 \mathrm{GW}_{\mathrm{e}}$ plant produced power for $3.6 \mathrm{k} / \mathrm{kW}_{\mathrm{e}} \mathrm{h}$ wich is economically competitive with coal and nuclear power.

\section{CONCLUSIONS}

We have examined the COE of HIB fusion power plants in nrder to determine the econumic impact of vaxious design and system improvements. Jur conclusions fall into four majur areas.

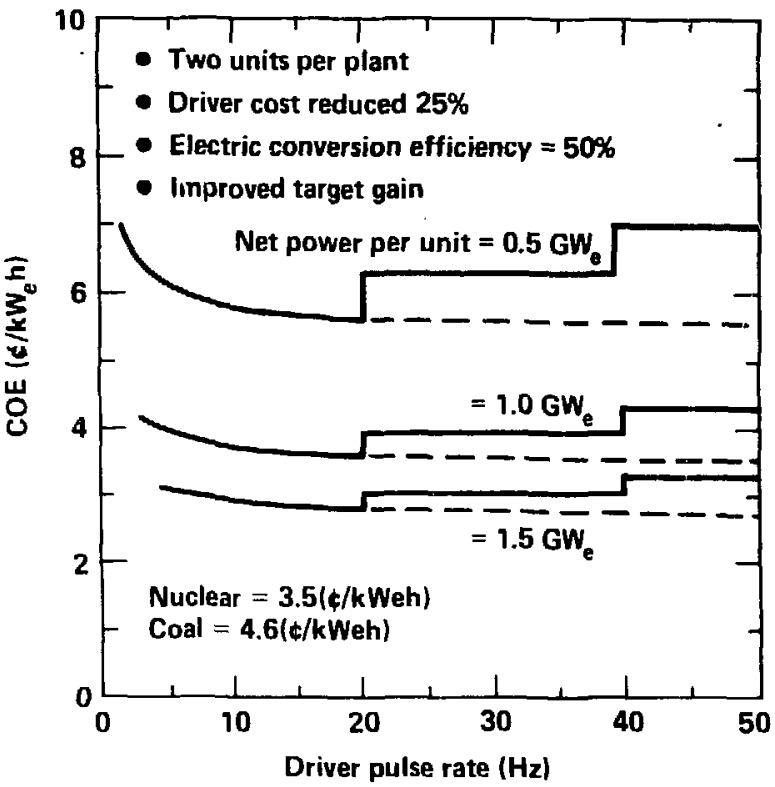

Fig. 6 With several simuitaneous improvements, the COE from HIB fusion power plants will be competitive with nuciear and coal.

\section{Pulse Rate}

For the single-unit, $1 \mathrm{GW}$ power plant, the optimum pulse rate (for both driver and chamber) is $25-30 \mathrm{~Hz}$, resulting in a COE of $6.7 \mathrm{Se} / \mathrm{kW}_{\mathrm{e}} \mathrm{h}$. However, the COE is not very serisilive to pulse rate. For example, if the chamber pulse rate is limited to $5 \mathrm{~Hz}$, the COE increases by less than $10 \%$. This is important because there are mejor uncertainties associated with predicting the maximum achievable chamber pulse rate. We also note that vecreasing the driver cost or increasing the plant size results in a lower optimum pulse rate but also in less sensitivity to pulse rate (1.e., flatter curves). Improvir.g the target gain by reducing the required driver energy for a given gain, results in a higher optimum pulse rate and a greater sensitivity. Increasing the electric conversion efficiency has little effect on the location of the optimum pulse rate.

\section{Multiple Reaction Chambers}

For the conditions examined here, using multiple reaction chambers at constant net power never improved the COE. The optimum driver pulse rate in every case was at the maximum achievable pulse rate of a single reaction chamber. This is due to the large cost ( $\$ 100 \mathrm{H})$ direct of adding beam transport lines for each new chamber and to the insensitivity to pulse rate of the COE curves. 


\section{Economy of Scale}

As expected, the COE decreases with increasing net electric power. The reduction is significant whether the power is increased by increasing the power of a single unit, or by using a single driver to operate several power units. These savings result from the fact that the driver is such a large fraction of the plant cost. Only if the cost of the driver is significantly reduced will the penalty for small power units be significantly affected.

We note that for a given net power, a multi-unit plant ichieves most of the economy of scale advantage: of a single large ,.lant. Because the difference is so small, a plant construction scencirio of starting small (0.5 GW or less) and adding power units might be particularly attrictive. In this way, revenues can be cullected from the first units while the later units are constructed as neecied. Other acivantages of smaller units, such as reduced on-site construction costs due to insreased factory fabrication and shortened construction periods, have not yet been consided in our siudies. These will tend to reduce the COE penalty of plants made up of several, smaller power units.

\section{Various Design Improvements}

Reducing the HIB driver cost is important. A $25 \%$ reduction in the driver cost leads to a $13 \%$ reduction in the COE. Improving target performance is also important. If the same target gain can be achleved with a factor of 3 less driver energy, the COE can be reduced by $12 \%$. Improving the electric conversion efficiency is not as advantageous as might be expected at first glance. Increasing the conversion efficiency from 40 to $60 \%$ reduces the COE by $12 \%$. However, this assumes that the power unit cost per $k w_{t}$ does not increase with increasing efficiency. If it does the savings will be even less.

Only a combination of improvements reduces the COE to values in the range of those forecast for future coal and fission plants. Such a combination of improvements is not unreasonable, however. For example, if the oriver cost is reduced $25 \%$, the target gain improved at low $E_{d}$ and the electric conversion efficiency increased to $50 \%$, and a two-unit plant is built ( $2 \mathrm{GW}_{\mathrm{e}}$ total), then the COE is competitive.

\section{SUMELARY}

We find that the COE from HIB fusion car be competitive with other future energy sources. Staged construction of multi-unit plants may make smaller initial plant sizes more attractive. Chamber pulse rates of 5-10 $\mathrm{Hz}$ appear adequate to achieve these economic goals.

\section{REFERENCES}

1. W. R. MEIER and W. J. HOGAN, Ident ifying Heavy Ion Beam Fusion Design and System Features with High Economic Leverage, LLNL report, UCRL (February 1985).

2. J. G. DELENE, et al, Nuclear Energy Cost Data Base - a Reference Data Base for Nuclear and Coal-fired Powerplant Power Generation Cost Analysis, U. S. Department of Energy Report, DDE/NE-0044/2 (March 1984).

3. Energy Economic Data Base (EEDB) Program Phase VI Update (1983) Report, United Engineers and Constructors Report, Philadelphia, PA, UE\&C-ORNL-840630 (June 1984).

4. Conceptual Designs of a Laser Fusion Power Plant, Part I, An Integrated Facility, pr.epared by Bechtel Group, Inc., San rrancisco, CA for Lawrence Livermore Naticnal Laboratory, LLNL report UCRL-15467 (July 1981).

5. B. BAOGER, et al., HIBALL - A Conceptual Heavy Ion Beam Driven Fusion Reactor Study, University of Wisconsin, Madison, Wisc., KFK3202 and UWFUM-450.

6. W. B. HERRMANNSFELOT, Economic Aspects of Heavy Ion Fusion, Stanford Linear Accelerator Lab Report, SLAC-PUB-3282 (January 1984).

7. J. D. LINDL, J. W-K. MARK, Recent Livermore Estimates of the Energy Gain of Cryogenic Single-Shell Ion Beam Targets, Lawrence Livermore National Laboratory Report UCRL-90241 (January 1984).

8. J. NUCKOLLS, "Economic Potential of Inertial Fusion," Presentation at Lawrence Livermore National Laboratory (April 1984). 